\title{
Lasers as a Current Therapeutic Strategy in Urological Practice
}

Ki Kyung Kim

Department of Urology, Kangnam Sacred Heart Hospital, College of Medicine, Hallym University, Seoul, Korea

Received December 4, 2014

Revised December 17, 2014

Accepted December 18, 2014

\section{Correspondence}

Ki Kyung Kim

Department of Urology, Kangnam Sacred Heart Hospital, College of Medicine, Hallym University, 1 Singil-ro, Youngdeungpo-gu, Seoul 150-071, Korea

Tel: +82-2-829-5198

Fax: +82-2-846-5198

E-mail: kimkk337@gmail.com

(C) Korean Society for Laser Medicine and Surgery

(c) This is an open access article distributed under the terms of the Creative Commons Attribution NonCommercial License (http://creativecommons.org/ licenses/by-nc/3.0) which permits unrestricted noncommercial use, distribution, and reproduction in any medium, provided the original work is properly cited.
Medical laser (light amplification by stimulated emission of radiation) is one of the various efficient and safe modalities for diagnosis and treatment of medical disease. Use of laser technology in the medical field has been expanded over decades and its use in urological practice has also been advanced, particularly in treatment of benign prostate hyperplasia (BPH), fragmentation of urinary stones, incision of strictures of the urinary tract, eradication of various tumor lesions of the skin and bladder urothelial cancer. Review of the history and evolution of lasers for better understanding of their roles in clinical practice will be worthwhile.

\section{Key words}

Laser; Urology 


\section{INTRODUCTION}

Physical principles of laser action is that the different systems produce different qualitative and quantitative effects in tissue according to their characters in terms of reflection, scattering, absorption and extinction length. The real biological effects of the lasers are coagulation or vaporization of tissues derived from their characters such as tissue penetration, thermal effect, and reflection. ${ }^{1}$ These days, the most popular lasers in urological practices are the Holmium:YAG laser and potassium-titanyl-phosphate (KTP), but Holmium:YAG laser is especially excellent for stone fragmentation and tissue ablation. The introduction of thinner and flexible laser fibers made their usage more effective and wider in application.

\section{HISTORY OF THE LASERS}

In 1917, the basic concept of 'laser' had been derived from the theory of 'stimulated emission' proposed first by Albert Einstein. ${ }^{2}$ In 1954, the first MASER Imicrowave amplification by stimulated emission of radiation) had been tested by Gordon et al. ${ }^{3}$ The stimulated emission at microwave wavelengths $(12.5 \mathrm{~mm})$ was demonstrated. and this maser developed to laser while consecutive 3 years.

In 1960, the world's first laser in practice had been introduced by Theodore, ${ }^{4}$ using ruby crystals as an active medium and built the world's first laser at Hughes Research in the USA.

The carbon dioxide laser $\left(\mathrm{CO}_{2}\right.$ laser) invented by Kumar Patel ${ }^{5}$ of Bell Labs in 1964 was one of the earliest gas lasers producing a infrared light, continuous wave with the wavelength of around 9.4 and 10.6 micrometers. $\mathrm{CO}_{2}$ lasers are still one of being most widely used in industrial applications for cutting, welding, and engraving due to the high power levels and reasonable cost.

They are also very useful in surgical procedures because of their water-absorbable character.

In the beginning, gas had been used as active medium for lasers, such as nitrogen (N), carbon dioxide (CO2), helium ( $\mathrm{He}$ ) and neon ( $\mathrm{Ne}$ ). Liquids medium has been followed soon in the name of "dye laser" using organic dye. Dye lasers have the advantage of being able to generate amplified light with a wider range of wavelengths, and some are even tunable. One of the earliest solid-state medium was Nd:YAG (neodymiumdoped yttrium aluminium garnet) and this laser has been most popular in medical practices today. ${ }^{\text {. }}$

\section{LASERS IN UROLOGICAL PRACTICES}

Lasers have been remarkably evolved into various techniques and types more efficient and safer in practical medicine, meanwhile lasers in urological practice have been around for more than 40 years. In 1980's, there was a remarkable evolution in urological laser practices. ${ }^{8}$

Since 1985, many Nd:YAG laser-driven transurethral treatments have been described for both benign prostatic enlargement and obstruction. ${ }^{\text {? }}$

The most common usages of laser in urological practice are for surgical treatments of $\mathrm{BPH}$, fragmentation of stones, coagulation of the vessels, ablation of various tumors and skin lesions, and incising strictures of the urinary tract. ${ }^{8}$ In addition, there is a photodynamic therapy for treatment of superficial bladder tumor. ${ }^{10}$ The types of the laser are Nd:YAG, KTP (potassium titanyl phosphate), Ho:YAG (holmium:YAG), Thu:YAG (thulium:YAG), $\mathrm{CO}_{2}$ (carbon dioxide), $\mathrm{LBO}$ ( $\mathrm{LiB}_{3} \mathrm{O}_{5}$, lithium triborate), and Diode laser.

\section{TREATMENT OF THE BPH}

The most popular and gold standard of surgery of BPH is still transurethral resection of the prostate (TURP). However, this may cause some problems such as bleeding during and after operation (needing transfusion in 5-11\%), urethral catheterization for 5-7 days, infrequent but serious TURP syndrome (in $1.4 \%$ of patients in large TURP), etc. ${ }^{11,12}$ To get rid of these disadvantages, various types of laser had been introduced in early 1990. In 1986, use of laser for removal of the enlarged benign prostatic tissue was first described and introduction of the "sidefiring" laser accelerated more widespread use of this modality.

At the beginning, treatment of BPH with Nd:YAG laser were very expected with low morbidity and symptom improvement. However, they are not used anymore because of their low tissue resection ability, low longterm outcomes, longer urethral catheterization, dysuria and bladder irritative symptoms, etc. ${ }^{13}$

KTP laser and Ho:YAG laser are recently most popular in urological practice. However, the volume reduction of the BPH just by vaporization and coagulation of these lasers by them has limitation on surgical effect in terms of removal of the adenoma of the enlarged prostate. So, new Holmium Laser Enucleation of the Prostate (HoLEP) having the same effect as the open prostatectomy is going to be a new gold standard of the surgical resection of the prostate replacing the conventional TURP. 


\section{$\mathrm{Nd}$ :YAG laser}

Visual laser ablation of the prostate (VLAP) is one of the earliest Nd:YAG laser for treatment of BPH.

Interstitial laser coagulation (ILC) first described in 1993 by Hofstetter. ${ }^{14}$ This is performed by placing the laser fiber directly into the prostatic adenoma and necrotizing that with preservation of the prostatic urothelium.

\section{Potassium-titanyl-phosphate (KTP) laser}

KTP laser is one of more advanced laser which is characterized by $532 \mathrm{~nm}$ in wavelength, $0.8 \mathrm{~mm}$ of penetrating depth, and strongly photoselective to oxyhemoglobin rather than water. This reveals rapid vaporization and excellent coagulation of the BPH tissue.

In late 1980, low power (20 W, 34 W) KTP laser was introduced for incision of the bladder neck and stricture of the urinary tract. ${ }^{15}$ The high power 80 W KTP laser recently developed had been reported that it can be performed under local anesthesia, at outpatients clinic base, with rare complications, and the same therapeutic effect as good as the TURP. ${ }^{16}$

Following the "High-power" KTP (80 W) laser, 120 W high power KTP laser called as HPS (High Performance System) has been recently developed, which has a aircooling system rather than water-cooling system of conventional KTP laser and is more rapid and effective in removal of the big $\mathrm{BPH} .^{17}$

\section{Lithium triborate $\left(\mathrm{LiB}_{3} \mathrm{O}_{5}, \mathrm{LBO}\right)$}

The $120 \mathrm{~W}$ lithium triborate (LBO) laser was the next generation to the $532 \mathrm{~nm}$ lasers. This was known that tissue ablation is faster and more efficient and the working distance is also increased up to $3 \mathrm{~mm}$. However, this has a reduced hemostatic ability in an ex vivo model. ${ }^{18,19}$

\section{Ho:YAG laser}

Holmium laser developed recently has the advantages of efficient incision, less heat loss, excellent coagulation. ${ }^{20,21}$ Holmium laser with 2,140 nm wavelength enables precise, char-free and virtually bloodless incision in prostatic tissue.

\section{Holmium laser enucleation of the prostate (HoLEP)}

The enucleation means total removal of the adenoma of the prostate at the level of the surgical capsule as a whole and this HoLEP method was particularly settled down as a promising alternative to TURP called as a gold standard of treatment of the BPH as well as open prostatectomy. This method has the additional advantages such as short placement of the urerthral catheter, less bleeding regardless of the size of the prostate even in patients with heart disease and on anticoagulative drugs. ${ }^{22,23}$

\section{Thu:YAG laser}

The Thu:YAG laser is the newest one and its use for BPH surgery was first published in 2005. ${ }^{24}$

Thulium laser enucleation of the prostate (ThuLEP)

Thu:YAG has a more improved ability for vaporization and smooth incision of tissue, by which the accurate removal of the adenoma at the level of the surgical capsule of the prostate got easier and safer regardless of its size.

\section{Diode laser}

A $980 \mathrm{~nm}$ wavelength diode laser has been recently reported to have improved hemostasis during vaporization of the prostatic tissue in comparison with a $120 \mathrm{~W}$ LBO laser. However, this is also not used in urological practice because of its complications such as postoperative irritative symptoms and epididymitis. ${ }^{25}$

\section{FRAGMENTATION OF STONES}

\section{Coumarin green dye laser}

The use of the laser for stone fragmentation had been first reported in 1987, using the pulsed Coumarin green dye laser MDL-1 Lasertripter (Candela Laser, Wayland, MA) ${ }^{26}$ This was a very enabling endoscopic fragmentation of more than $80-95 \%$ of stones with rare urothelial injury. However, it is problematic for fragmentation of hard stones composed of calcium oxalate monohydrate and cystine. $^{27}$

\section{Alexandrite laser}

The alexandrite laser was introduced in 1991 but this has not been applied in fragmentation of the stones as a lithotriptor bacause of the high costs. ${ }^{28}$

\section{Frequency Doubled Double-pulse Nd:YAG (FREDDY)}

FREDDY laser was the next step in laser lithotripsy. ${ }^{29,30}$ This laser produce two pulses at different wave-length: a 20\% green light component at $532 \mathrm{~nm}$ and an $80 \%$ infrared component at 1,064 $\mathrm{nm}$. This synergistic combination of the lasers enables highly effective fragmentation of the stones with negligible effect on soft tissue. ${ }^{30}$ However, this FREDDY laser enables only effective fragmentation of the dark or colored stones other than hard and colorless stones. So, this laser is called ' $50 \%$ laser' because only about $50 \%$ of stones could be treated with it. ${ }^{31}$ 


\section{Ho:YAG laser}

Ho:YAG laser currently became the most popular lithotrite because its photothermal mechanism acts effectively on fragmentation of stones regardless of their sizes and locations with thinner flexible endoscope and laser probe. ${ }^{32,33}$ The combination of the actively deflectable, flexible ureteroscope facilitated clearance of stones even lower-pole caliceal calculi. ${ }^{33}$

\section{Erbium:YAG (Er:YAG) laser}

Er:YAG laser operating at a wavelength of $2940 \mathrm{~nm}$ is a new one introduced recently. Although It has been reported that the Er:YAG laser seems to be slightly more effective than the holmium laser at breaking up stones in early studies, it has some limitations to be defined more. ${ }^{34}$

\section{LASER FOR TREATMENT OF THE STRICTURES OF THE UPPER AND LOWER URINARY TRACT}

Endoscopic incision and vaporization of the fibrotic tissue of the stricture site without thermal and mechanical damage to the surrounding normal tissue using Ho:YAG has some advantages in comparison with the conventional methods with a cold knife, electrical incision, and sound dilation. ${ }^{35}$ However, there are some reports that the treatment using lasers seemed to be effective but revealed a high recurrence rate of up to $70.1 \%$ at a mean of 15.2 months. ${ }^{36}$

More recently, the Thu:YAG laser with low penetrating depth (only $0.3 \mathrm{~mm}$ ) and Ho:YAG laser are known to be more effective. ${ }^{35,37}$

\section{TREATMENT OF THE OTHER CANCERS AND SKIN LESIONS}

\section{Treatment of transitional cell carcinoma in the renal pelvis and ureter}

The Nd:YAG laser and the Ho:YAG laser have been used for treatment of transitional cell carcinoma. Parsons was the first to experimentally use a pulsed ruby laser on an opened canine bladder. ${ }^{38}$ The development of the thin and flexible ureterorenoscopes and fine biopsy devices have gotten the laser treatment of troublesome tumors safe and effective.

\section{Photodynamic therapy (PDT) for the bladder cancer}

This is especially one of the disngostic and therapeutic modalities of the superficial bladder tumors. ${ }^{10}$

The photosensitizing agents applied intravesically or intreavenously and light of specific wavelength acting on them are needed. These photosensitizers are absorbed into the all kinds of cells. The photosensitizers in the normal cells are disappeared within 2 days but those accumulated in cancer cells abnormally generate a toxic agent, activated oxygen by cystoscopically lasering light with specific wavelength $(630-690 \mathrm{~nm})$ and this toxic agent may destruct the cancer cells, damage to the vascular endothelium and localized inflammation. ${ }^{39}$

The most popular laser for this is the diode lasers being able to produce the desired wavelengths of most photosensitizer drugs $(630-760 \mathrm{~nm}) .^{40}$

\section{CONCLUSIONS}

The year 2010 marks the 50th anniversary of the laser since 1960 when the world's first laser in practice had been introduced by Theodore. ${ }^{4}$ Meanwhile, laser technology has evolved tremendously. However, some of these lasers had been disappeared in medical practice because of their incompleteness. There is still plenty of room for further improvement. Anyway, in the near future, more up-graded, safe and effective laser technology will be appeared.

\section{REFERENCES}

1. Teichmann HO, Herrmann TR, Bach T. Technical aspects of lasers in urology. World J Urol 2007;25:221-5.

2. Einstein A. Zur Quantentheorie der Strahlung. Phys Z 1917;18: $121-8$.

3. Gordon JP, Zeiger HJ, Townes CH. Molecular microwave oscillator and new hyperfine structure in the microwave spectrum of NH3. Phys Rev 1954;95:282-4.

4. Maiman TH. Stimulated optical radiation in ruby. Nature 1960; 187:493-4.

5. Patel CKN. Continuous-wave laser action on vibrationalrotational transitions of CO2. Phys Rev 1964;136:A1187-93.

6. Gross AJ, Herrmann TR. History of lasers. World J Urol 2007; 25:217-20.

7. Geusic JE, Marcos HW, van Uitert LG. Laser oscillations in Nddoped yttrium aluminum, yttrium gallium, and gadolinium garnets. Appl Phys Lett 1964;4:182-4.

8. Marks AJ, Teichman JM. Lasers in clinical urology: state of the art and new horizons. World J Urol 2007;25:227-33.

9. Shanberg AM, Lee IS, Tansey LA, Sawyer DE. Extensive neodymium-YAG photoirradiation of the prostate in men with obstructive prostatism. Urology 1994:43:467-71.

10. Jocham D, Stepp H, Waidelich R. Photodynamic diagnosis in urology: state-of-the-art. Eur Urol 2008;53:1138-48.

11. AUA Practice Guidelines Committee. AUA guideline on management of benign prostatic hyperplasia (2003). Chapter 1 : 
Diagnosis and treatment recommendations. J Urol 2003;170: 530-47.

12. Reich O, Gratzke C, Bachmann A, Seitz M, Schlenker B, Hermanek P, et al; Urology Section of the Bavarian Working Group for Quality Assurance. Morbidity, mortality and early outcome of transurethral resection of the prostate: a prospective multicenter evaluation of 10,654 patients. J Urol 2008;180:246-9.

13. Issa MM. Laser therapy for BPH. AUA Update Series 2003;22: 90-5.

14. Hofstetter A, Alvarez Alarcón-Hofstetter A. Treatment of prostatic tumors with interstitial thermocoagulation with neodymium-YAG la new treatment in minimally invasive surgeryl. Arch Esp Urol 1993;46:317-9.

15. Farsi HM. Visual laser ablation of the prostate for patients with acute urinary retention. Br J Urol 1996;78:90-2.

16. Te AE, Malloy TR, Stein BS, Ulchaker JC, Nseyo UO, Hai MA, et al. Photoselective vaporization of the prostate for the treatment of benign prostatic hyperplasia: 12-month results from the first United States multicenter prospective trial. J Urol 2004;172: 1404-8.

17. Spaliviero M, Araki M, Wong C. Short-term outcomes of Greenlight HPS laser photoselective vaporization prostatectomy (PVP) for benign prostatic hyperplasia (BPH). J Endourol 2008;22:2341-7.

18. Wosnitzer MS, Rutman MP. KTP/LBO laser vaporization of the prostate. Urol Clin North Am 2009;36:471-83.

19. Heinrich E, Wendt-Nordahl G, Honeck P, Alken P, Knoll T, Michel MS, et al. $120 \mathrm{~W}$ lithium triborate laser for photoselective vaporization of the prostate: comparison with $80 \mathrm{~W}$ potassiumtitanyl-phosphate laser in an ex-vivo model. J Endourol 2010; 24:75-9.

20. Nishioka NS, Domankevitz Y, Flotte TJ, Anderson RR. Ablation of rabbit liver, stomach, and colon with a pulsed holmium laser. Gastroenterology 1989;96:831-7.

21. Kuntz RM. Current role of lasers in the treatment of benign prostatic hyperplasia (BPH). Eur Urol 2006;49:961-9.

22. Tyson MD, Lerner LB. Safety of holmium laser enucleation of the prostate in anticoagulated patients. J Endourol 2009;23: 1343-6.

23. Neill MG, Gilling PJ, Kennett KM, Frampton CM, Westenberg $A M$, Fraundorfer MR, et al. Randomized trial comparing holmium laser enucleation of prostate with plasmakinetic enucleation of prostate for treatment of benign prostatic hyperplasia. Urology 2006;68:1020-4.

24. Xia SJ, Zhang YN, Lu J, Sun XW, Zhang J, Zhu YY, et al. Thulium laser resection of prostate-tangerine technique in treatment of benign prostate hyperplasia. Zhonghua Yi Xue Za Zhi 2005;85:
3225-8.

25. Chiang $\mathrm{PH}$, Chen $\mathrm{CH}$, Kang $\mathrm{CH}$, Chuang YC. GreenLight HPS laser $120-W$ versus diode laser $200-W$ vaporization of the prostate: comparative clinical experience. Lasers Surg Med 2010;42:624-9.

26. Dretler SP, Watson G, Parrish JA, Murray S. Pulsed dye laser fragmentation of ureteral calculi: initial clinical experience. J Urol 1987;137:386-9.

27. Floratos DL, de la Rosette JJ. Lasers in urology. BJU Int 1999; 84:204-11.

28. Pearle MS, Sech SM, Cobb CG, Riley JR, Clark PJ, Preminger $G M$, et al. Safety and efficacy of the Alexandrite laser for the treatment of renal and ureteral calculi. Urology 1998;51:33-8.

29. Marks AJ, Teichman JM. Lasers in clinical urology: state of the art and new horizons. World J Urol 2007;25:227-33

30. Yates J, Zabbo A, Pareek G. A comparison of the FREDDY and holmium lasers during ureteroscopic lithotripsy. Lasers Surg Med 2007;39:637-40.

31. Dubosq F, Pasqui F, Girard F, Beley S, Lesaux N, Gattegno $B$, et al. Endoscopic lithotripsy and the FREDDY laser: initial experience. J Endourol 2006;20:296-9.

32. Lee J, Gianduzzo TR. Advances in laser technology in urology. Urol Clin North Am 2009;36:189-98.

33. Vassar GJ, Chan KF, Teichman JM, Glickman RD, Weintraub ST, Pfefer TJ, et al. Holmium: YAG lithotripsy: photothermal mechanism. J Endourol 1999;13:181-90.

34. Fried NM. Potential applications of the erbium:YAG laser in endourology. J Endourol 2001;15:889-94.

35. Futao S, Wentong Z, Yan Z, Qingyu D, Aiwu L. Application of endoscopic Ho:YAG laser incision technique treating urethral strictures and urethral atresias in pediatric patients. Pediatr Surg Int 2006;22:514-8.

36. Becker HC, Miller J, Nöske HD, Klask JP, Weidner W. Transurethral laser urethrotomy with argon laser: experience with 900 urethrotomies in 450 patients from 1978 to 1993. Urol Int 1995;55:150-3.

37. Wang L, Wang Z, Yang B, Yang Q, Sun Y. Thulium laser urethrotomy for urethral stricture: a preliminary report. Lasers Surg Med 2010;42:620-3.

38. Anson K, Seenivasagam K, Miller R, Watson G. The role of lasers in urology. Br J Urol 1994;73:225-30.

39. Pinthus JH, Bogaards A, Weersink R, Wilson BC, Trachtenberg J. Photodynamic therapy for urological malignancies: past to current approaches. J Urol 2006;175:1201-7.

40. Stables GI, Stringer MR, Robinson DJ, Ash DV. Erythroplasia of Queyrat treated by topical aminolaevulinic acid photodynamic therapy. Br J Dermatol 1999;140:514-7. 